\title{
ВЗАИМОДЕЙСТВИЕ ВЛАСТИ, БИЗНЕСА И ОБЩЕСТВА КАК ИНСТРУМЕНТ УКРЕПЛЕНИЯ КОНКУРЕНТОСПОСОБНОСТИ РЕГИОНА
}

\section{COOPERATION BETWEEN STATE, BUSINESS, AND SOCIETY AS AN INSTRUMENT OF REGIONAL COMPETITIVENESS INCREASE}

\section{N. Alenteva}

Summary. Efficient management of regional development becomes a relevant objective for the state principally and for definite regions particularly in connection with solving the problem regarding eliminating factors, intensifying differences. In this context the regions with large area, various natural, climate, cultural, and historic conditions request deeper consideration of the reasons which block the social and economic development. One of such regions is Far East, while social and economic development of this region remains a priority issue of the state policy, focused on development of such infrastructures as transport, energetic, communal service, telecommunication, and social sphere. With respect to multi aspect regional development it is necessary to accommodate goals and interests of all economic actors, i.e. state, business, and society. For these purposes the relevant question refer to prove development of the Far East region on the basis of cooperation between economic actors, to define organization schemes regarding strengthening cooperation taking into account possible risks.

Keywords: cooperation, region, sustainable development, competitiveness, state, business, society.

\author{
Алентьева Надежда Геннадиевна \\ Аспирант, Финансовый университет при \\ Правительстве Российской Федерации (Москва); \\ Стариий преподаватель, Институт международного \\ права и экономики имени А.С. Грибоедова (Москва) \\ nadyapg@list.ru
}

Аннотация. Эффективное управление региональным развитием является актуальной задачей, как для государства в целом, так и для отдельных территорий в частности в связи с необходимостью решения вопроса по устранению факторов, усиливающих дифференциацию развития регионов. При этом регионы, обладающие наибольшей площадью в стране, разнообразными природными, климатическими, культурными, историческими условиями, требуют особенно глубокого рассмотрения причин, являющихся препятствием социально-экономического развития. Одним из таких регионов является Дальний Восток, социальное и экономическое развитие которого остается приоритетной задачей государственной политики, ориентированной на развитие таких инфраструктурных направлений, как транспорт, энергетика, коммунальное хозяйство, телекоммуникации, социальная сфера. Принимая во внимание широко аспектное развитие региона, следует учитывать интересы и цели всех субъектов экономики: государства, бизнеса и общества. В связи с этим актуальным становятся вопросы по разработке, обоснованию развития регионов нового освоения Дальнего Востока на основе взаимодействия всех субъектов, а также выявлению организационных схем по укреплению взаимодействия с учетом возможных рисков и путей по их минимизации.

Ключевые слова: взаимодействие, регион, устойчивое развитие, конкурентоспособность, государство, бизнес, общество.

Отношения между государством, бизнесом и обществом характеризуют уровень развития общества. Основу социальной жизни представляют экономические отношения. Значение государства в рыночной экономике определяется его ролью независимого субъекта социальной сферы, учитывающего интересы всех членов общества. В настоящее время тройственный формат отношений власть-бизнес и общество встречается не так часто, гораздо чаще встречаются отношения власть и бизнес, власть и общество, общество и бизнес. Самым активным участником взаимодействия выступает государство: организует формат взаимодействия, осуществляет его контроль. После государства следующим участником по уровню активности выступает бизнес: взаимодействует с властью по своей инициативе. Наименее активным участником взаимодействия является 
общество [1]. Государственная власть взаимодействует с предпринимательским сектором посредством следующих инструментов: кредитно-финансовая система, государственный заказ, делегирование ряда полномочий государственного сектора частному, государственно-частные партнерства, особые экономические зоны, технопарки. Трехсторонний формат взаимодействия требует определенных действий со стороны всех участников: со стороны гражданского общества - понимание основных потребностей и формирование социального заказа; со стороны государства - определение направлений развития, мотивация бизнес структур по вопросам корпоративной ответственности, поддержка в сфере совершенствования институтов гражданского общества; со стороны бизнеса - эффективное ведение предпринимательской деятельности, выполнение социальных обязательств [2].

Среди основных препятствий, влияющих на повышение динамики социально-экономического развития, следует выделить устойчивость страны в целом и регионов в частности к неблагоприятным воздействиям. В связи с этим высокий уровень конкурентоспособности на микро-, мезо-, макроуровнях экономики влияет на укрепление устойчивости и темпы развития, что приобретает особенную значимость в настоящее время в условиях новых рисков и вызовов, возникающих на мега уровне экономики. Таким образом, устойчивое развитие зависит от таких условий, как анализ степени устойчивости и управление устойчивым развитием [3]. Учитывая региональный характер устойчивости, следует уделить внимание интересам всех хозяйствующих субъектов, а также инструментам их взаимодействия [11]. Поэтому в задачи эффективного управления включаются следующие: определение механизмов, которые не будут подвергаться влиянию неблагоприятных событий и, напротив, при их наступлении будут способствовать устойчивому развитию в процессе объединения усилий всех участников взаимодействия. На поступательное развитие региона влияет множество факторов всех уровней экономики: объем инвестиций, политическая стабильность, изменение цен на ресурсы, техногенные катастрофы и др. Учесть все возможные риски достаточно сложно, но определить конкурентную привлекательность региона представляется возможным за счет анализа динамики основных социально-экономических показателей, а также уровня развития отраслей инфраструктуры, непосредственно влияющих на конкурентоспособность.

В настоящее время среди задач Правительства РФ указано обеспечение ускоренного социально-экономического развития Дальнего Востока в соответствии с Указом Президента РФ от 26.06.2020 № 427 «О мерах по социально-экономическому развитию Дальнего Вос- тока». При этом основными направлениями социально-экономического развития являются: ускорение экономического роста, развитие человеческого капитала и кадрового потенциала, формирование комфортной среды для жизни, технологическое развитие.

Социально-экономическое освоение территорий предполагает наличие необходимых основных экономических и инфраструктурных объектов, которые характеризуют следующие показатели: плотность населения (на 1км2), количество основных фондов, плотность железнодорожных и автомобильных дорог [8]. Сопоставление данных показателей в Дальневосточном федеральном округе с показателями по всем субъектам Российской Федерации позволяет сделать следующие выводы: площадь территории составляет более $40 \%$ от площади всей страны, при этом численность населения - 5,6\%, фондооснащенность - 5,7\% и плотность автомобильных дорог - менее 1\% [12]. В целях выявления причин снижения темпов экономического роста необходимо, прежде всего, определить ключевые значения социально-экономического развития Дальневосточного федерального округа. Основными показателями по определению благополучия и экономического развития являются валовой региональный продукт, денежные доходы населения, начисленная заработная плата, численность рабочей силы, коэффициент естественной убыли населения, миграционный отток населения. Анализ темпов роста (снижения) основных социально-экономических показателей свидетельствует о том, что на протяжении более пяти лет удельный вес субъекта ДФО в валовом региональном продукте составляет порядка 5\% (один из самых низких показателей в стране). При этом наименьший удельный вес принадлежит Северо-Кавказскому федеральному округу и составляет более $2 \%$. Наибольший удельный вес принадлежит Центральному федеральному округу и составляет более $30 \%$. При этом основным видом экономической деятельности по объему отгруженных товаров в ДФО принадлежит добыче полезных ископаемых (13\%) [12]. Дальнейший анализ экономических показателей позволяет сделать следующие выводы: среди всех 8 округов Российской Федерации Дальневосточный федеральный округ занимает следующие позиции: 8 место по удельному весу автомобильных дорог с твердым покрытием в общей протяженности автомобильных дорог общего пользования, 4 место по обороту розничной торговли на душу населения, 5 место по числу персональных компьютеров на 100 работников, 3 место по среднедушевым денежным доходам (в месяц), 2 место по среднемесячной номинальной заработной плате работников организации, 3 место по уровню занятости, 6 место по уровню безработицы, 7 место по общей площади жилых помещений, приходящихся в среднем на одного жителя, 6 место по числу собственных легковых автомобилей на 1000 человек насе- 
ления, 7 место по численности студентов, обучающихся по программам высшего образования на 1000 человек населения [12].

По статистическим данным также можно сравнить интегральный индекс развития инфраструктуры в ДФО со среднероссийским значением и оценить минимальную дополнительную потребность в развитии инфраструктуры [13]. В 6 субъектах ДФО индекс развития инфраструктуры ниже среднего показателя по стране: республика Бурятия, республика Саха (Якутия), Забайкальский край, Приморский край, Амурская область, Еврейская автономная область. При этом минимальная дополнительная потребность в инвестициях в 2020 г. выросла более чем на 28\% по сравнению с 2019 г. в ДФО в целом, с 180,2 млрд. руб. в 2019 г. до 231,5 млрд. руб. в 2020 г. Таким образом, одним из основных факторов, сдерживающих социально-экономическое развитие Дальнего Востока, следует выделить низкий уровень по обеспечению инфраструктуры: транспортной, социальной, жилищно-коммунальной и коммуникационной. Об этом указано в Национальной программе социально-экономического развития Дальнего Востока на период до 2024 года и на перспективу до 2035 года, утвержденной распоряжением Правительства Российской Федерации от 24 сентября 2020 г. № 2464-р.

В настоящее время миссия государственной политики на Дальнем Востоке связана с обеспечением конкурентоспособных условий для инвестиций и предпринимательской деятельности. В связи с этим механизмами реализации являются следующие: территории опережающего развития, инфраструктурная поддержка инвестиционных проектов, бесплатное предоставление земельных участков для граждан Российской Федерации, снижение тарифов на электроэнергию для предприятий, приоритеты государственных программ с целью развития Дальнего Востока, льготное ипотечное кредитование, льготное финансирование крупных инвестиционных проектов, а также мелких и средних предпринимателей.

Таким образом, принимая во внимание миссию государственной политики на Дальнем Востоке необходимо определить те условия, которые будут укреплять конкурентоспособность данного округа с учетом имеющихся ресурсов и специфики территорий нового освоения.

Среди действующих форм взаимодействия государства, бизнеса и общества получили распространение государственно-частные партнерства. Анализ динамики распространения ГЧП проектов В ДФО позволяет сделать следующие выводы: общий объем инвестиций в проекты составляет с 2006 по 2020 гг. порядка 17 млр. руб., менее 1\% от всего объема ГЧП в стране, при этом основной сферой распространения является комму- нально-энергетическая, более $86 \%$. Однако сравнивая анализ развития инфраструктуры с возрастающей необходимостью ее развития в объеме более 231 млрд.руб., можно сделать вывод, что к настоящему времени доля участия государственно-частных партнерств в развитии инфраструктуры составляет чуть более 8\%. Таким образом, возникает необходимость дальнейшего поиска и укрепления механизмов взаимодействия государства, бизнеса и общества.

Следует отметить, что главным субъектом на современном этапе развития технологий и основным фактором эффективной деятельности на всех уровнях экономики является человеческий ресурс, т.е. основу новой конкурентоспособной экономики формируют профессиональные специалисты, способные решить неординарные задачи. При этом конкурентные преимущества достигаются в процессе постоянного обучения, самосовершенствования, обмена опытом в компаниях, занимающих лидирующие позиции в отрасли. Очевидно, что в том случае, если организация не учитывает динамичные изменения внешней среды, в конечном итоге рискует обанкротиться [9]. Более того, если данная тенденция сохраняется не только на микро-, но и макроуровне экономики, последствия снижения конкурентоспособности приведут к сокращению объема инвестиций в регион. В связи с этим в экономике, основанной на знаниях, возникает необходимость в подготовке таких специалистов, которые способствуют и стимулируют непрерывное развитие, а также повышают квалификацию сотрудников на предприятии. В условиях сформировавшейся виртуальной мобильности возможности современных средств связи позволяют сокращать расходы на образовательные программы [9]. Следует учитывать тот факт, что среди стимулов развития национальной экономики особенно следует выделить цифровую экономику, т.к. внедрение цифровых технологий способствует повышению конкурентоспособности путем повышения совокупной факторной производительности $[4 ; 6]$. При этом эффективная модель управления регионом на основе соблюдения правовых, социально-экономических, организационных и методических положений способна обеспечить устойчивый экономический рост [10; 7].

Таким образом, на социально-экономическое развитие региона влияет решение, прежде всего, основных проблемных вопросов для региона, являющихся в достаточной степени индивидуальными для каждого субъекта. В связи с этим учет данных степени развития сфер инфраструктуры и стимулирование взаимодействия государственной власти, бизнеса, общества в соответствующих сферах экономики способны обеспечить устойчивое развитие региона, в результате которого будет достигнут рост основных социально-экономических показателей, а также уровня и качества жизни населения. 


\section{ЛИТЕРАТУРА}

1. Взаимодействие власти, бизнеса и общества в современных условиях: монография / С.А. Стрижов; под общ.ред. С.А. Стрижова. - Москва: РуСАЙНС, 2016. - $150 \mathrm{c}$.

2. Грекова Г.И. Взаимодействие власти, бизнеса и гражданского общества в современной России: вопросы теории и практики / Г.И. Грекова, М.В. Киварина.—- Великий Новгород: НовГУ им. Ярослава Мудрого, 2016. - 231 с.

3. Гринчель Б.М. Методы анализы и управления устойчивым развитием экономики регионов / Б.М. Гринчель, Е.А. Назарова // Экономика и управление.2020.—№ 1 (171). - C. 23-34.

4. Лещев С.В. Умный интерфейс, разумная среда, искусственный интеллект: метафоры ментализма и энвайронментализма / С.В. Лещев, Н.Б. Миронова // Гуманитарные науки и образование.- 2014. — № 1 (17). — С. 91-96.

5. Лобанова А.В. Управление формированием и развитием механизма взаимодействия региональной власти, бизнес- структур и гражданского общества / А.В. Лобанова // Экономика и управление в XXI веке: тенденции развития.— 2013.— № 11.—C. 59-65.

6. Мавлютина Г.А. Устойчивое развитие цифровой экономики как элемент обеспечения национальной безопасности Российской Федерации / Г.А. Мавлютина, Е.Б. Ножкина, П.Л. Алтухов // Экономическая безопасность и качество.— 2018. — № 1 (30).— C. 19-24.

7. Панина 0.В. Механизм управления устойчивым развитием экономики региона / 0.В. Панина, Л.Р. Добрина // Вестник университета.— 2014.— № 17. C. 71-75.

8. Смагин Б.И. Освоенность территории региона: теоретические и практические аспекты: монография / Б.И. Смагин. - Мичуринск: Издательство МичГАУ, 2007.- $124 \mathrm{c}$.

9. Тинякова В.И. Трансформация системы профессиональной подготовки кадров, конкурентоспособных в условиях экономики, основанной на знаниях / В.И. Тинякова, Н.И. Морозова, В.К. Гунин // Экономика устойчивого развития. — 2019. — № 1 (37). — С. 242-245.

10. Шедько Ю.Н. Модель управления устойчивым развитием региона / Ю.Н. Шедько // Экономика и предпринимательство. — 2016. — № 11-3 (76).— C. $214-221$

11. Шедько Ю.Н. Факторы и условия устойчивости развития региона: синергетика взаимодействия / Ю.Н. Шедько // Вестник Московского государственного областного университета. Серия «Экономика».— 2014.— № 4. - С. $49-55$.

12. Федеральная служба государственной статистики [Электронный ресурс].— - Режим доступа: https://rosstat.gov.ru

13. Индекс развития инфраструктуры России [Электронный ресурс]. - Режим доступа: http://infraone-research.ru

(c) Алентьева Надежда Геннадиевна (nadyapg@list.ru ).

Журнал «Современная наука: актуальные проблемы теории и практики»

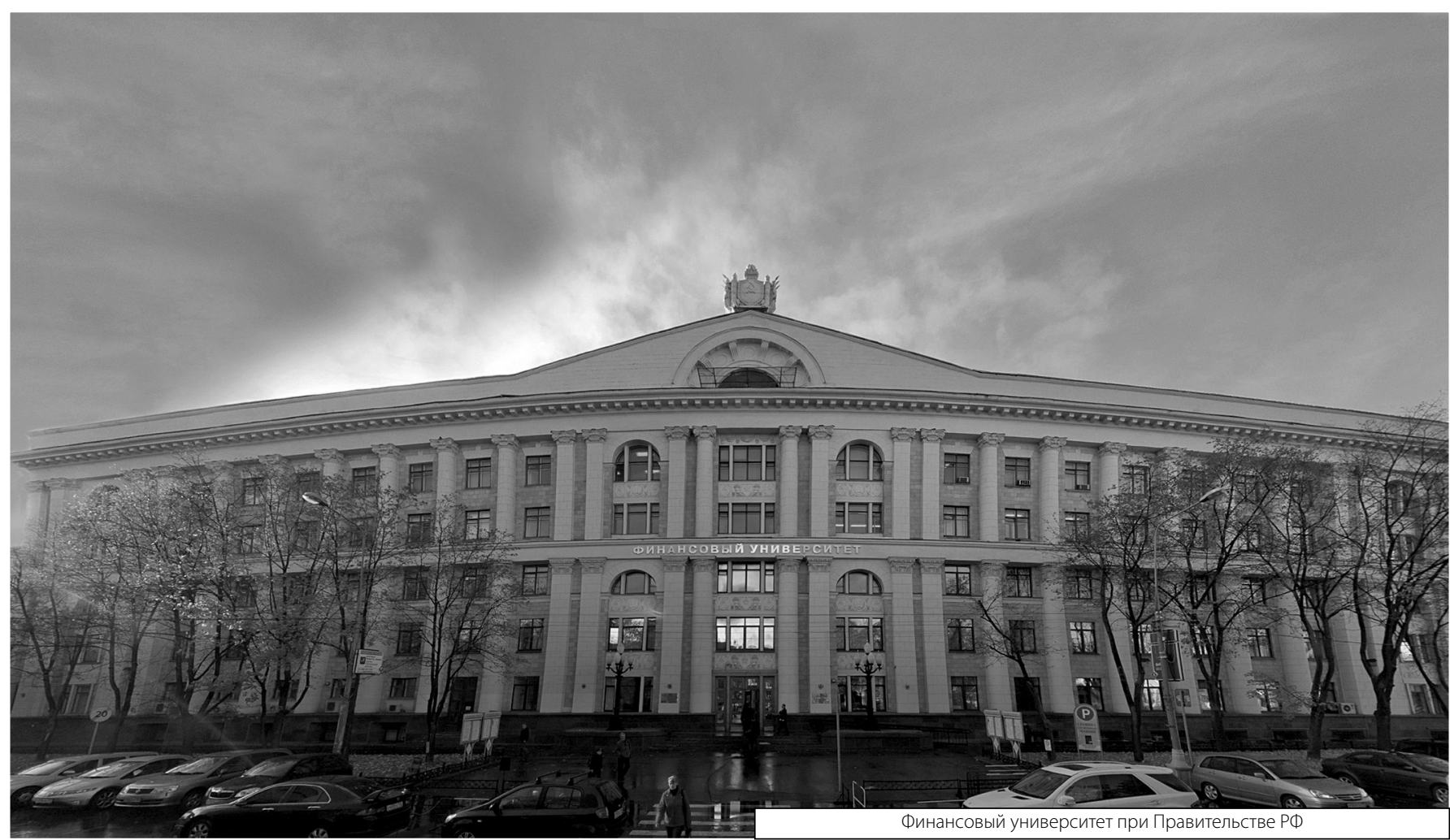

